\title{
Small farms might rescue the future
}

\author{
Review by Hannah Lohr * \\ University of Kansas
}

Review of $A$ Small Farm Future: Making the Case for a Society Built Around Local Economies, Self-Provisioning, Agricultural Diversity, and a Shared Earth, by Chris Smaje. (2020). Chelsea Green Publishing. Available as Kindle and paperback; 320 pages. Publisher's website: https://www.chelseagreen.com/product/a-small-farm-future/

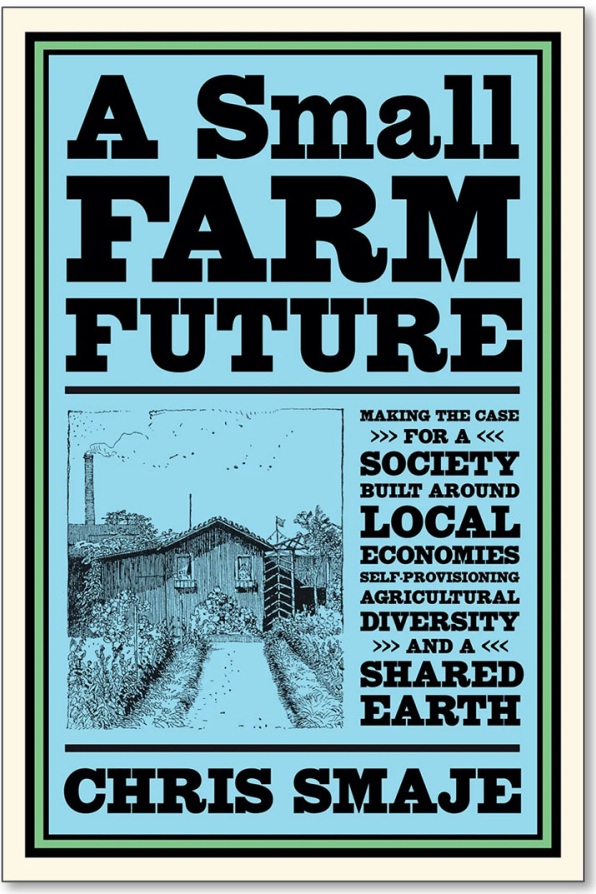

Submitted December 31, 2020 / Revised January 11, 2021 / Published online March 22, 2021

Citation: Lohr, H. (2021). Small farms might rescue the future [Book review]. Journal of Agriculture, Food Systems, and Community Development, 10(2), 583-585. https://doi.org/10.5304/jafscd.2021.102.041

Copyright (C) 2021 by the Author. Published by the Lyson Center for Civic Agriculture and Food Systems. Open access under CC-BY license.

$I^{\prime}$ $\mathrm{n}$ A Small Farm Future, Chris Smaje argues that small farms offer humanity's strongest option for a just and ecologically and nutritionally sustainable future. He undertakes three major feats. First, he demonstrates that certain forces are driving humanity toward a small farm future in which local and self-sufficient food production is likely. Second, he outlines the ways in which a small farm future solves most of the world's looming crises (see chapter 1). Without concrete demarcations of small or local, Smaje argues for a future

* Hannah Lohr is a Ph.D. candidate in sociology at the University of Kansas. She has conducted research alongside rural, smallholder farmers and is currently engaged in food justice and urban farming research. She can be reached at 1415 Jayhawk Blvd., 716 Fraser Hall; Lawrence, KS 66045 USA; hdevries@ku.edu in which much of the world population works as small-scale farmers creating "local-autonomies" and "a degree of self-provisioning" (p. 9). Third, he depicts what such a small farm future might look like.

Section I (chapters 1-3) begins by outlining 10 major crises related to population, climate, energy, soil, stuff, water, land, health and nutrition, the political economy, and culture. In short, these crises are embodied by finite resources that promote unjust and unsustainable consequences. This section demonstrates that these crises cannot be solved by technical, one-shot solutions under the direction of global capitalist progress. Furthermore, Smaje emphasizes a need to envision a future that can address the diversity of crises among an array of global circumstances. This necessarily involves 
what Robert Nozick calls multiple utopias, in which solutions are flexible but intentionally driven toward universally just sustainability (chapter 2). A local, small farm future offers the adaptability needed for the variety of world circumstances while enabling widespread farming practices that could reverse climate trajectories.

While Smaje provides much insight into these future utopias and how we might get there, he emphasizes this future would inevitably require "widespread material self-provision" (p. 87) in which individuals, families, and communities become stewards of their material necessities. Importantly, Smaje argues that current cultural and political economic values promote endless consumption at the expense of others. He suggests these might only be dissuaded by engaging with nature itselfsomething a self-provisioned agriculture would allow. In addition, widespread local economies could also make nutritious food accessible worldwide. Though Smaje recognizes some scholars criticize essentialist views in support of returns to peasantry, his case rests on assumptions that some people today, and arguably more in the future, would want to engage in smallholder farming (chapter 3).

Section II (chapters 4-11) discusses the agroecological frameworks such a future might adopt in order to mitigate the crises discussed in section I. Smaje argues that ecosystem farming with low energy and low labor inputs hardly yields high enough outputs, but high input agriculture alongside economic modernization has largely contributed to many of our current problems, exacerbating injustices through much of the world (chapters 4, 5, and 10). Looking to minimize energy inputs while still yielding high outputs, a small farm future will likely involve intensification (most often through human labor), biomimicry inspired by, but not an exact replica of, wild ecosystems (see also chapters 8 and 9 ), and widely distributed farms across landscapes that feed local communities (chapter 6 and 7). Such widespread farming ecologies would not only help deter crises associated with dwindling resources, they could also drastically reduce emissions that contribute to rising global temperatures, contributing significantly to population and climate crises. Smaje concludes this section with a compelling case for a small farm future. His model of 2050 England accounts for population growth, effects from climate catastrophes, energy input declines, and caloric nutritional requirements, while also demonstrating that civilization can indeed thrive within an alternative agricultural restructuring (chapter 11).

Despite the plausibility of a small farm future, section III (chapters 12-16) addresses the social conditions in support of and needed for a smallholder agricultural future. Notably, gender inequities that arise in household-level farming would need to be combatted by a shift in both cultural consciousness and institutional safeguards (chapter 12). Furthermore, it would necessarily involve changes in land ownership (chapter 13), capitalist economies (chapter 14), distributions of the population across the land (chapter 16), and religious and scientific values (chapter 16).

The final section (IV) of the book outlines the global political dilemmas facing a small farm future. Recognizing that a transition may seem far-fetched, Smaje demonstrates that the combination of looming environmental and economic crises is likely to prompt a political watershed that promotes a new politics, perhaps in support of local autonomies and equitable outcomes (chapter 17). Although imperfect, civic republicanism, for example, safeguards against prejudice, while lending itself to localism in which values, rather than the sum of individual desires, guide citizens' behavior (chapter 18). He concludes the book by admitting to the vagueness of his prescriptions but proposing that a multitude of political (among other social and ecological) options might enable a better future (chapter 19). Such a future, Smaje argues, would still involve a return to the land, cultivation of local livelihoods, and less reliance on economic capitalism.

While I think Smaje's argument is sound, my first criticism stems from his modelling techniques that are based solely on projections for Britain's 2050 farming. Although he acknowledges some of its shortcomings, amid projections of the changing climate, other regions of the world are likely to experience harsher realities, restricting the generalizability of this model for other regions. Second, despite the array of ground Smaje covers in the 
book, his argument for local autonomies and selfprovisioned farming fails to address the inadequacies of these structures should disaster strike, wiping out food supplies for a large proportion of a region, or even a single farmer. As anthropogenic warming is expected to worsen disasters in severity and frequency, safeguards for especially vulnerable communities worldwide would need to be in place. A Small Farm Future provides a critical starting point for scholars and practitioners alike in a range of disciplines including food justice, utopian stud- ies, agricultural or climate policy, and rural development. It is well suited for advanced undergraduate or graduate seminars in environmental or social sciences. Despite the promising avenues a widespread alternative agricultural future could provide, Smaje is attuned to the realities such a feat would require. His portrayal accomplishes, not only the ecological viability, but the social, economic, and political necessities-in my opinion, a difficult task. 